\title{
STUDI ETNOFARMASI TUMBUHAN JERNANG PADA SUKU ANAK DALAM DI DESA MUARA KILIS
}

\section{STUDY OF ETHNOPHARMACY PLANT OF JERNANG ON SUKU ANAK DALAM IN MUARA KILIS VILLAGE}

\author{
Lili Andriani ${ }^{1}$, Awaliatuwelda $^{1}$, Santi Perawati ${ }^{1 *}$ \\ ${ }^{1}$ Prodi Farmasi, Sekolah Tinggi Ilmu Kesehatan Harapan Ibu Jambi, Jambi
}

Naskah diterima tanggal 25 Oktober 2020

\begin{abstract}
Jernang is one of the forest results in the Suku Anak Dalam (SAD) in Muara Kilis village, Central District Ilir, Tebo Regency, Jambi, which is economically valuable and can be used as a traditional medicine. One of the ways of developing this traditional medicine is by doing ethnopharmacy. This research aims to determine the aspect of the ethnopharmaceutical aspects and how it is processing as traditional medicine. Data collection method was obtained through interviews on informants with sampling in the form of purposive sampling technique. The results showed that there were 2 species of Jernang in Muara Kilis village, namely Jernang Kuau (Daemonorops draco (Willd) Blume.) and Jernang Kelukup (Daemonorops sp). The Jernang has the same efficacy in traditional medicine for the treatment of abdominal pain, bloody cough, bleeding bowel movements, postnatal bleeding and wounds, while the ecological functions of the fruit Jernang is as a natural clothing dye. The process of processing rattan fruit to treat various diseases by treating it into juice mixed with turmeric. In addition, to overcome the wounds of Jernang rattan fruit is made into powders and applied to the wound skin. So Jernang can be used as a traditional medicine that cure various diseases.
\end{abstract}

Keywords: Daemonorops draco (Willd.) Blume., Daemonorops $s p$, ethnopharmacy, SukuAnak Dalam (SAD)

\begin{abstract}
ABSTRAK
Jernang adalah salah satu hasil hutan pada Suku Anak Dalam (SAD) di Desa Muara kilis, Kecamatan Tengah ilir, Kabupaten Tebo, Jambi yang bernilai ekonomis tinggi serta dapat dijadikan sebagai obat tradisional. Salah satu cara pengembangan obat tradisional ini dengan melakukan etnofarmasi. Penelitian ini bertujuan untuk mengetahui aspek etnofarmasi jernang serta bagaimana cara pengolahannya sebagai obat tradisional. Metode pengumpulan data dilakukan melalui wawancara terhadap informan dengan pengambilan sampel berupa teknik purposive sampling. Hasil penelitian menunjukkan bahwa ada 2 spesies jernang di Desa Muara Kilis, yaitu jernang kuau (Daemonorops draco (Willd) Blume.) dan jernang kelukup (Daemonorops $s p$ ). Jernang tersebut memiliki khasiat yang sama dalam hal pengobatan tradisional pada bagian getahnya yaitu untuk pengobatan penyakit sakit perut, batuk berdarah, buang air besar berdarah, pendarahan pasca melahirkan dan luka, sedangkan fungsi ekologis dari buah ịernang adalah sebagai pewarna pakaian alami. Proses pengo!ahan buah rotan jernang untuk mengobati berbagai penyakit dengan cara mengolahnya menjadi jus yang dicampur dengan kunyit. Selain itu untuk mengatasi luka buah rotan jernang dibuat menjadi serbuk dan dioleskan pada bagian kulit yang luka. Jadi jernang dapat dijadikan sebagai obat tradisional yang menyembuhkan berbagai penyakit.
\end{abstract}

Kata Kunci: Daemonorops draco (Willd.) Blume, Daemonorops sp, Etnofarmasi, Suku Anak Dalam (SAD) 


\section{PENDAHULUAN}

Obat tradisional banyak digunakan oleh masyarakat menengah ke bawah terutama pada masyarakat Suku Anak Dalam (SAD), salah satunya SAD yang terdapat di Desa Muara Kilis, Kecamatan Tengah Ilir, Kabupaten Tebo. SAD memanfaatkan bermacam jenis satwa dan tumbuhan yang memiliki pola pemanfaatan yang beragam salah satunya tumbuhan jernang (Daemonorops sp). Di Jambi jernang telah ada dan dimanfaatkan oleh masyarakat sejak zaman dahulu, umumnya digunakan sebagai ramuan obat untuk mengobati kencing darah, sariawan, sakit perut, diare, dan gangguan pencernaan lainnya (Yetti et al, 2013).

Di Eropa, getah jernang digunakan sebagai bahan baku obat-obatan seperti obat sakit disentri dan diare. Di Malaysia, getah jernang digunakan sebagai bahan pengobatan gangguan pencernaan. Sedangkan di Indonesia, jernang digunakan sebagai bahan ramuan obat untuk diare, penyakit kencing darah, sariawan dan sakit perut. Di Yunani, pada masa lalu jernang digunakan sebagai bahan obat sakit mata(Perawati, 2017), (Yetti et al, 2013).

Pemanfaatan tumbuhan lokal perlahan namun pasti telah tersingkir dari peradaban. Salah satu sebabnya adalah kebijakan yang hanya terfokus pada sumber nasional yang mengabaikan sumber-sumber dari alam. Pengembangan jenis-jenis sumber daya alam hanya terbatas dilakukan oleh masyarakat pedalaman atau masyarakat adat yang memanfaatkannya dalam lingkup kecil secara lokal untuk kebutuhannya sendiri(Khairiyah et al., 2016). Untuk pengembangan obat tradisional dengan berbagai pendekatan secara ilmiah ialah dengan melakukan etnofarmasi. Dalam penelitian etnofarmasi, yang menjadi objek utama dalam penelitian adalah sebuah komunitas yang terisolasi untuk menemukan kembali resep tradisional dan mencoba melakukan evaluasi secara biologis (Fajrin et al., 2015).

Tumbuhan jernang sebelumnya telah dilakukan studi etnobotani untuk mengetahui jenis dan manfaatnya sebagai obat tradisional, pada masyarakat desa Lamban Sigatal dan Sepintun, Kecamatan Pauh, Kabupaten Sarolangun, Jambi (Yetti et al., 2013). Jernang berkhasiat sebagai obat luka, sakit gigi dan sehabis melahirkan. Selain itu tumbuhan jernang juga berkhasiat sebagai obat BAB berdarah pada masyarakat Kaili Moma di Kecamatan Kulawi, Kabupaten Sigi, Provinsi Sulawesi Tengah (Islami et al., 2017). Sedangkan untuk di desa Muara Kilis, Kecamatan Tengah Ilir, Kabupaten Tebo, Provinsi Jambi, tumbuhan jernang ini belum pernah dilaporkan mengenai pemanfaatannya sebagai obat tradisional.

\section{METODE PENELITIAN \\ Pemilihan Sampel}

Penelitian ini dilakukan di desa Muara Kilis, Kecamatan Tengah Ilir, Kabupaten Tebo, Provinsi Jambi. Penelitian ini menggunakan metode teknik purposive sampling dan teknik pengumpulan data berupa wawancara (openended interview) dan merupakan penelitian deskriptif. Teknik pengambilan sampel yang digunakan dalam penelitian ini yaitu purposive sampling. Sampel yang dipilih yaitu dengan pertimbangan tertentu, dalam hal ini yang dianggap paling tahu tentang tumbuhan jernang, yaitu kepala adat, tumenggung, dukun, ataupun masyarakat tertentu (Khairiyah et al., 2016). Berdasarkan hasil survei diketahui bahwa yang informan yang mengetahui terkait tumbuhan jernang adalah Bapak Apung sebagai Tumenggung dan Bapak Hazril sebagai Dukun.

\section{Wawancara Informan}

Teknik wawancara dilakukan dengan menggunakan open-ended interview. Tahap pertama dari studi lapangan yaitu, para informan ditanya terkait dengan tumbuhan jernang, seperti penggunaan sebagai obat tradisional, bagaimana cara memperolehnya, bagian apa yang dimanfaatkan, dan bagaimana cara pengolahan tumbuhan jernang tersebut terkait pengobatan tradisional (Khairiyah et al., 2016).

\section{HASIL DAN PEMBAHASAN}

Berdasarkan wawancara dengan informan (Tumenggung dan Dukun) didapatkan 2 jenis tumbuhan jernang yang berbeda di Desa Muara Kilis, Kecamatan Tengah Ilir, Kabupaten Tebo. Hasil identifikasi di Herbarium Jatinagor Bandung dan Herbarium Bogoriense diperoleh spesies dan famili setiap jenis jernang. Ada beberapa spesies jernang penghasil resin diantaranya Daemonorops draco Blume, Daemonorops didymophilla Becc, Daemonorops brathystachys Furtado, Daemonorops draconcellus Becc, Daemonorops mattanensis Becc, Daemonorops propincua Becc, dan Daemonorops micracantha (Grift) Matt. ( Ridwan dkk., 2018) (Tabel 1).

Kedua jernang tersebut memiliki manfaat yang sama dalam hal pengobatan tradisional. Morfologi pada tumbuhan jernang juga hampir sama hanya saja getah pada jernang kelukup lebih tipis (Tabel 2). Hasil wawancara dari kedua informan didapatkan hasil mengenai manfaat dan cara pengolahan tumbuhan jernang sebagai obat tradisional (Tabel 3). Kandungan metabolit sekunder yang terdapat pada jernang kuau dan jernang kelukup dapat dilihat pada Tabel 4. Di mana metabolit sekunder pada masing-masing organ tumbuhan menunjukkan metabolit sekunder yang berbeda. 
Tabel 1. Tumbuhan jernang yang terdapat di Desa Muara Kilis

\begin{tabular}{cccc}
\hline No & Nama daerah & Spesies & Famili \\
\hline 1 & Jernang kuau & Daemonorops draco (Willd.) Blume & Arecaceae \\
2 & Jernang kelukup & Daemonorops sp. & Arecaceae \\
\hline
\end{tabular}

Berdasarkan informasi dari Kepala Desa Muara Kilis, jumlah penduduk SAD di desa Muara Kilis yaitu 48 Kepala Keluarga, 205 jiwa. SAD menempati rumah yang mereka bangun sendiri di kawasan mereka. Bahasa yang digunakan suku SAD adalah cabang dari rumpun bahasa Melayu dan sangat mirip dengan bahasa Jambi. Umumnya masyarakat SAD bekerja sebagai pencari jernang, sawit, dan karet. Mereka hanya memanfaatkan sumber daya alam yang berasal dari hutan.

Sebagian besar SAD yang terdapat di desa Muara Kilis ini sudah memeluk agama Islam, tetapi sebagian dari mereka masih memegang kepercayaan Animisme, dan sihir. Dalam pandangan SAD, kemampuan sihir (supranatural) diturunkan dari nenek moyang mereka. Masyarakat SAD telah lama memanfaatkan tumbuh-tumbuhan sebagai bahan pengobatan tradisional, salah satunya tumbuhan jernang. Pada penelitian yang telah dilakukan wawancara terhadap dua orang informan, yaitu Bapak Apung sebagai
Tumenggung dan Bapak Hazril sebagai Dukun, diketahui bahwa terdapat dua jenis jernang di desa Muara Kilis, yaitu jernang kuau dan jernang kelukup.

Kedua jenis jernang ini dilakukan indentifikasi tumbuhan dengan tujuan untuk mengidentifikasi tumbuhan yang berupa famili dan spesies dari tumbuhan jernang tersebut, dilakukan oleh Herbarium Jatinangor Bandung, Herbarium Bogoriense Bogor dan Herbarium Anda Sumatra Barat. Didapatkan spesies dan famili setiap jenis jernang, yaitu jernang kuau (Daemonorops draco (Willd). Blume.) dan jernang kelukup (Daemonorops sp.). Daemonorops draco (Willd). Blume yang terdapat di desa Muara Kilis Jambi memiliki batang yang sangat berduri dan berumpun, berwarna coklat kemerahan. Tumbuhan jernang ini juga memiliki sistem perakaran serabut, warna daun hijau kekuningan serta berduri kasar dipermukaan daun. Pertulangan daun sejajar dan berpelepah. Bentuk buah bulat agak oval dan berwarna merah pekat dengan bagian buah

Tabel 2. Morfologi tumbuhan jernang

\begin{tabular}{|c|c|c|c|c|c|}
\hline & \multicolumn{3}{|c|}{ Daemonorops draco (Willd.)Blume } & \multicolumn{2}{|c|}{ Daemonorops sp. } \\
\hline No & $\begin{array}{l}\text { Bagian } \\
\text { jernang }\end{array}$ & $\begin{array}{c}\text { Hasil } \\
\text { pengamatan }\end{array}$ & $\begin{array}{l}\text { Literatur (Yetti } \\
\text { et al., 2013) }\end{array}$ & Hasil pengamatan & $\begin{array}{l}\text { Literatur } \\
\text { (Yetti et } \\
\text { al., 2013) }\end{array}$ \\
\hline 1 & $\begin{array}{l}\text { Bentuk } \\
\text { Buah }\end{array}$ & Bulat, bersisik & Panjang & Oval, bersisik & $\begin{array}{l}\text { Panjang, bulat, } \\
\text { oval }\end{array}$ \\
\hline 2 & $\begin{array}{l}\text { Warna } \\
\text { buah }\end{array}$ & Merah pekat & Merah & Merah kecoklatan & Merah \\
\hline 3 & $\begin{array}{l}\text { Pertulangan } \\
\text { daun }\end{array}$ & Sejajar & Sejajar & Sejajar & Sejajar \\
\hline 4 & $\begin{array}{l}\text { Permukaan } \\
\text { Daun }\end{array}$ & Kasar & Kasar & Kasar & $\begin{array}{l}\text { Kasar, } \\
\text { kasar }\end{array}$ \\
\hline 5 & $\begin{array}{l}\text { Warna } \\
\text { Daun }\end{array}$ & $\begin{array}{l}\text { Hijau } \\
\text { kekuningan }\end{array}$ & $\begin{array}{l}\text { Hijau } \\
\text { kekuningan }\end{array}$ & Hijau & $\begin{array}{l}\text { Hijau } \\
\text { kekuningan, } \\
\text { hijau }\end{array}$ \\
\hline 6 & $\begin{array}{l}\text { Bentuk } \\
\text { Daun }\end{array}$ & Linear & & Oval & Linear, oval \\
\hline 7 & Batang & $\begin{array}{l}\text { Beruas, berduri, } \\
\text { berumpun }\end{array}$ & $\begin{array}{l}\text { Berumpun, } \\
\text { berduri tidak } \\
\text { rapat }\end{array}$ & $\begin{array}{l}\text { Beruas, berduri, } \\
\text { tunggal }\end{array}$ & $\begin{array}{l}\text { Berumpun, } \\
\text { tunggal }\end{array}$ \\
\hline 8 & $\begin{array}{l}\text { Warna } \\
\text { batang }\end{array}$ & $\begin{array}{l}\text { Coklat } \\
\text { kemerahan }\end{array}$ & $\begin{array}{l}\text { Coklat } \\
\text { kemerahan }\end{array}$ & Coklat keputihan & $\begin{array}{l}\text { Coklat } \\
\text { kemeraham, } \\
\text { kehijauan, hijau } \\
\text { kecoklatan. }\end{array}$ \\
\hline $\begin{array}{l}9 \\
10\end{array}$ & $\begin{array}{l}\text { Akar } \\
\text { Getah Buah }\end{array}$ & $\begin{array}{l}\text { Akar serabut } \\
\text { Tebal }\end{array}$ & $\begin{array}{l}\text { Akar serabut } \\
\text { Tebal }\end{array}$ & $\begin{array}{l}\text { Akar serabut } \\
\text { Tipis }\end{array}$ & $\begin{array}{l}\text { Akar serabut } \\
\text { Tebal, tipis }\end{array}$ \\
\hline
\end{tabular}



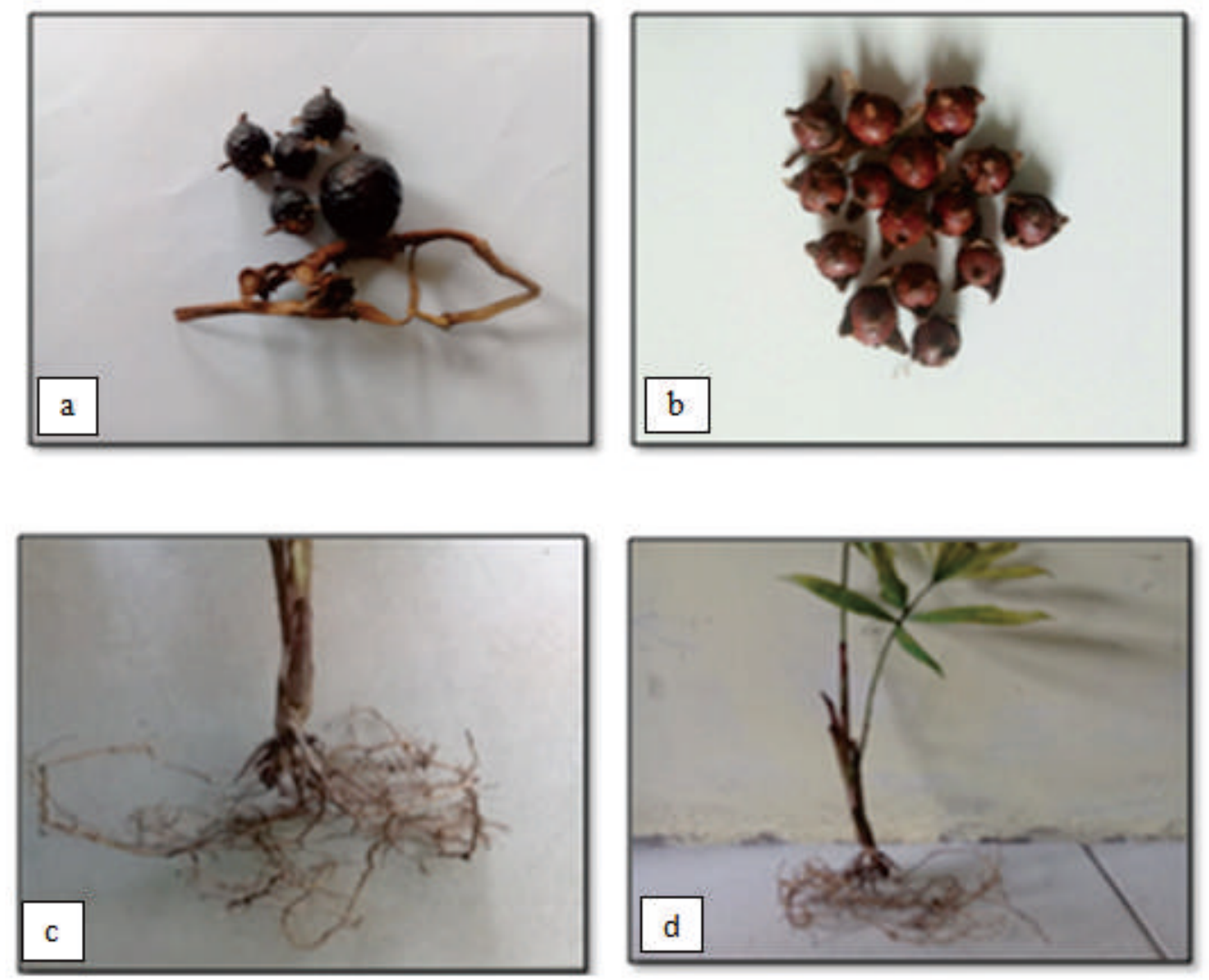

\section{Gambar 1. a) Buah Jernang Kuau; b) Buah Jernang Kelukup; c) Perakaran Jernang Kuau; d) Perakaran Jernang Kelukup}

terdiri dari kulit buah yang berupa sisik agak mengkilat. Jarak antar tangkai rapat, pelepah daun dan tangkai buah rapat sehingga apabila dipanen terlebih dahulu, pelepah harus dilepas dari batangnya sehingga baru bisa dilepas, getah buah tebal. Beda antara Jernang Kuau dan Jernang Kelukup dapat dilihat pada Gambar 1.

Jernang yang berasal dari jenis Daemonorops hanya terdapat di sebagian Malaysia dan di Indonesia. (Yi, et el, 2011). Daemonorops sp yang terdapat di desa Muara Kilis Jambi memiliki batang yang berduri jarang dan berwarna coklat keputihan, sistem perakaran serabut, warna daun hijau serta berduri kasar di permukaan daun, bentuk dari daun oval dengan pertulangan daun sejajar dan berpelepah. Sedangkan bentuk buah oval dan berwarna merah kekuningan dengan bagian buah terdiri dari kulit buah yang berupa sisik, getah buah tipis.

Jernang yang terdapat di Desa Muara Kilis ini umumnya dijadikan sebagai mata pencaharian masyarakat setempat, juga digunakan sebagai bahan pengobatan tradisional. Penyakit yang dapat disembuhkan menggunakan tumbuhan jernang ini adalah luka, sakit perut, batuk berdarah, buang air besar berdarah serta pendarahan pasca melahirkan. Cara pengolahan tumbuhan jernang sebagai obat tradisional seperti obat sakit perut, batuk berdarah, buang air besar berdarah, pendarahan pasca melahirkan adalah dengan cara buah ditumbuk halus, lalu di campurkan dengan perasan kunyit dan ditambahkan air lalu di saring dan diminumkan. Sedangkan untuk obat luka, buah jernang dapat langsung digunakan dengan cara ditumbuk dan langsung dioleskan pada kulit yang terluka, sedangkan buahnya sendiri juga dapat digunakan sebagai pewarna pakaian alami.

Daemonorops draco (Willd.) Blume. yang terdapat di Bukit Dua Belas, Sarolangun, Jambi merupakan obat tradisional yang digunakan SAD setempat sebagai obat untuk sakit kepala, obat bisul, luka, obat-obatan untuk diare, dan pewarna pakaian alami, dan dapat dimanfaatkan untuk bahan baku industri pernis, pembuatan cat dan bahan pewarna celupan "(Mairida et al., 2016), sedangkan masyarakat Desa Lamban Sigatan, Kabupaten Sarolangun juga memanfaatkan getah jernang sebagai obat sakit gigi. Pengolahannya dengan cara buah jernang yang telah ditumbuk, dicampur manggunakan satu sendok teh dan air kemudian diminum. Selain itu batang jernang juga dimanfaatkan untuk pembuatan tiang (Yetti et al., 2013). Selain di desa Muara killis jernang dengan nama latin Daemonorops draco ini juga ditemukan di desa Jebak kabupaten Batanghari Jambi dikenal dengan jernang rattan (Sulasmi et 
Tabel 3. Manfaat dan cara pengolahan jernang sebagai obat

\begin{tabular}{|c|c|c|c|}
\hline $\begin{array}{c}\text { Bagian yang } \\
\text { digunakan }\end{array}$ & Kegunaan & Cara pengolahan & $\begin{array}{c}\text { Cara } \\
\text { pemakaian }\end{array}$ \\
\hline \multirow{4}{*}{$\begin{array}{l}\text { Getah pada } \\
\text { buah }\end{array}$} & 1. Luka & $\begin{array}{l}\text { Buah ditumbuk, langsung } \\
\text { dioleskan pada kulit yang } \\
\text { terluka }\end{array}$ & $\begin{array}{c}\text { Dipakai } 3 x \\
\text { sehari dalam } 3 \\
\text { hari }\end{array}$ \\
\hline & 2. Sakit perut & \multirow{3}{*}{$\begin{array}{l}\text { Buah ditumbuk + perasan } \\
\text { kunyit }+ \text { air kemudian } \\
\text { disaring lalu diminum }\end{array}$} & \multirow{3}{*}{$\begin{array}{c}\text { Dipakai } 3 x \\
\text { sehari dalam } 3 \\
\text { hari }\end{array}$} \\
\hline & $\begin{array}{l}\text { 3. Batuk berdarah } \\
\text { 4. Pendarahan } \\
\text { pasca } \\
\text { melah irkan }\end{array}$ & & \\
\hline & 5. BAB berdarah & & \\
\hline
\end{tabular}

al., 2012). Jernang juga dimanfaatkan oleh masyarakat Talang Mamak yang berada di Bukit tiga puluh, Kabupaten Sarolangun sebagai pewarna kerajinan. Selain getah, buah rotan jernang sebagai obat, getah rotan manau (Calamus mannan Miq.) juga dimanfaatkan masyarakat Serampas, Jambi untuk mengobati sariawan, getah gitan labu (Willughbeia angustifolia) juga dimanfaatkan Suku Melayu Jambi sebagai obat penyakit dalam dan bahan perekat(Andhika et al., 2015).

Resin jernang dihasilkan dari buah jernang betina atau jernang hermaprodit. Resin didapatkan dari sel dan jaringan buah jernang (Asra dkk., 2012). Resin jernang mempunyai manfaat terhadap kesehatan yaitu untuk meningkatkan sirkulasi darah, memperbaiki regenerasi jaringan, penyembuhan terkilir, bisul, pendarahan, dan menghilangkan rasa sakit (Syamsuardi et al., 2014). Resin jernang juga sangat diminati oleh Negara Cina, Hongkong, dan Singapura, karena dilihat dari potensinya sebagai bahan obat secara biologis dan aktivitas farmakologis seperti antimikroba, antivirus, antitumor, dan aktivitas sitotoksik (Mawardi et al., 2017). Selain itu resin jernang juga bisa digunakan sebagai bahan aktif dalam pembuatan sediaan obat luka cair.

Penggunaan jernang sebagai obat tradisional pada SAD di Desa Muara Kilis dapat diberikan kesemua usia hanya saja dosisnya yang berbeda. Untuk anak- anak, biasanya hanya memerlukan setengah gelas atau 2 sampai 3 sendok makan ramuan jernang yang telah dibuat. Untuk orang dewasa menggunakan 1 gelas ramuan jernang. Obat ini biasanya digunakan dalam jangka waktu $3 x$ sehari (pagi siang - malam) setelah makan. Pemakaian akan dihentikan jika penyakit telah sembuh, dan jika tidak ada perubahan selama 3 hari, maka masyarakat SAD mengganggap obat yang dipakai tidak cocok dan menggantikannya dengan pengobatan lain. Pada masa menggunakan pengobatan secara tradisional khususnya getah buah jernang, masyarakat SAD selalu menghindari mengkonsumsi cabe atau makanan pedas yang mereka anggap dapat memperburuk keadaan tubuh. Pengobatan menggunakan getah jernang ini juga tidak memiliki efek samping pada penggunanya.

Pada penelitian yang telah dilakukan sebelumnya, komponen kimia utama pada resin jernang adalah resin ester dan dracoresino tannol (57- 82\%). Selain itu, resin juga mengandung senyawa-senyawa seperti dracoresene $(14 \%)$, dracoalban (hingga 2,5\%), resin tak larut $(0,3 \%)$, residu $(18,4 \%)$, asam benzoat, asam benzoilasetat, dracorhodin dan beberapa pigmen terutama nordracorhodin dan nordracorubin (Chu, 2006 dalam Risna, 2006). Dracorhodin dan turunnya digunakan sebagai pigmen pewarna, dan sebagai agen antitumor, (Baumer dan Dietermann, 2010; Andini et el, 2020). Penelitian lain yang telah dilakukan pada aktifitas

Tabel 4. Kandungan metabolit sekunder jernang kuau dan jernang kelukup

\begin{tabular}{llcccccc}
\hline \multirow{2}{*}{ No } & \multirow{2}{*}{ Organ } & \multicolumn{5}{c}{ Kandungan metabolit sekunder } \\
\cline { 3 - 7 } & & Alkaloid & Flavonoid & Saponin & Tanin & Steroid & Triterpenoid \\
\hline 1 & Buah & + & + & + & - & - & - \\
2 & Daun & + & - & - & - & - & - \\
3 & Batang & + & - & + & - & - & - \\
4 & Akar & - & - & + & - & - & - \\
\hline
\end{tabular}


antioksidan dan antikoagulasi resin jernang, diketahui bahwa kandungan metabolit sekunder yang terdapat pada buah jernang hanya flavonoid dan triterpenoid (Pasaribu et al., 2017).

Daemonorops draco (Willd.) Blume memiliki kandungan kimia dimana telah diuji berdasarkan penelitian sebelumnya yaitu 10.10Dimethyl -6-Methylen -1-Oxa-2-Phenyl Spiro(4.5)decan E (59,75\%); (e) -6-Methoxy -2(4- Hydroxybenzylidene) -1-Benzo Furan -3(2h)C (23,93\%); 2H-1-Benzopyran-7-on (9,59\%); Perclorate of 8 - Methoxy-2 phenylbenzo[b]thiopyrylium $(4,31 \%)$ dan Benzene (1,22\%), sedangkan Daemonorops sp adalah 10.10-Dimethyl -6-Methylen-1-Oxa-2Phenyl - Spiro(4.5)decane (60,59\%); 2 h -1Benzopyran-7-On (13,03\%); (e) -6-Methoxy -2(4- Hydroxybenz Ylidene)-1-Benzofuran -3(2h) -C (12,75\%); ; Styrene (1,29\%) dan Benzene $(0,82 \%)$ (Waluyo, 2013), berbeda halnya dengan tumbuhan jernang yang terdapat di Desa Muara Kilis, Kecamatan Tegah Ilir, Kabupaten Tebo Provinsi Jambi memiliki kandungan metabolit sekunder, yaitu pada buah jernang kuau dan kelukup adalah alkaloid, flavonoid, dan saponin. Namun pada daun jernang kuau dan kelukup kandungan yang terdapat hanya alkaloid, dan untuk batang jernang kuau dan kelukup adalah alkaloid dan saponin, sedangkan untuk akar pada jernang kuau dan kelukup hanya mengandung saponin saja.

Beberapa senyawa telah berhasil diisolasi dari jernang diantaranya senyawa dari golongan flavonoid. Ada 8 jenis turunan senyawa flavonoid daemoflavan dari spesies Daemonorops draco. Tiga diantaranya mempunyai aktivitas sebagai sitotoksik terhadap sel HepG2 (Wang et al.,2020). Dari jernang juga ditemukan senyawa yang berpotensial untuk dikembangkan sebagai obat antiinflamasi yaitu senyawa Flavan-3-ol-dihydroretrochalcones. Senyawa ini dapat menginhibisi produksi superoksida anion dari sel neutrophil manusia (Kuo et al., 2017).

Masyarakat desa Muara Kilis, Kecamatan Tengan Ilir, Kabupaten Tebo, Provinsi jambi telah memanfaatkan jernang sebagai obat tradisional, yaitu untuk obat luka, sakit perut, batuk berdarah, buang air besar berdarah, serta pendarahan pasca melahirkan, sedangkan buahnya juga dapat digunakan sebagai pewarna alami untuk pakaian. Cara pengolahan tumbuhan jernang sebagai obat tradisional untuk mengobati sakit perut, batuk berdarah, buang air besar berdarah, pendarahan pasca melahirkan adalah dengan cara buah ditumbuk dan diambil getahnya, lalu di campurkan dengan perasan kunyit dan ditambahkan air lalu di saring dan diminumkan. Sedangkan untuk obat luka, buah jernang dapat langsung digunakan dengan cara ditumbuk dan langsung dioleskan pada kulit yang terluka.

\section{UCAPAN TERIMAKASIH}

Terima kasih kepada masyarakat Desa Muara Kilis atas bantuan selama penelitian terkait SAD dan juga kepada Sekolah Tinggi IImu Kesehatan Harapan Ibu Jambi atas fasilitas sarana laboratorium selama penelitian berlangsung.

\section{DAFTAR PUSTAKA}

Andhika, R. R., Hariyadi, B., \& Saudagar, F. (2015). Etnobotani Penghasil Getah oleh Suku Anak Dalam di Taman Nasional Bukit Duabelas Kabupaten Sarolangun , Jambi (Etnobotany of Sap Producing Plants by Suku Anak Dalam in the National park Bukit Dua Belas Sarolangun, Jambi). Jurnal IImu Pertanian Indonesia, 20 (April), 33-38.

Andini, R., Ismullah, F., Bakri, S., M.I Sulaiman and A Anhar. (2020). Current status of Aceh jernang (Daemonorops sp.) and its traditional conservation efforts. IOP Conf. Series: Earth and Environmental Science 482 (2020) 012035

Asra, R., Syamsuardi., Mansyurdin., dan Witono, JR. (2012). Rasio seks jernang (daemonorops draco (willd.)blume) pada populasi alami dan budidaya: implikasi untuk produksi biji. Buletin kebun raya. 15(1):1-9.

Baumer, U. and P. Dietemann. (2010). Identification and differentiation of dragon's blood in works of art using gas chromatography/ mass spectrometry. Anal Bioanal Chem. 397(3):1363-1376.

Fajrin, M., Ibrahim, N., \& Wahyu Nugrahani, A. (2015). Studi Etnofarmasi Suku Dondo Kecamatan Dondo Kabupaten Tolitoli Sulawesi Tengah. Journal of Pharmacy, 1(October), 92-98.

Islami, M. Y., Ibrahim, N., \& Nugrahani, A. W. (2017). Studi Etnofarmasi Suku Kaili Moma Di Kecamatan Kulawi , Kabupaten Sigi, Provinsi Sulawesi Tengah Ethnomedicinal Study Of Kaili Moma Tribe In Kulawi Subdistrict, Sigi Regency, Central Sulawesi . Journal of Pharmacy, 3(March), 27-33.

Khairiyah, N., Anam, S., \& Khumaidi, A. (2016). Studi Etnofarmasi Tumbuhan Berkhasiat Obat Pada Suku Banggai di Kabupaten Banggai Laut, Provinsi Sulawesi Tengah. Journal of Pharmacy, 2(1).

Kuo, PC., Hung, HY., Hwang, TL., Du, WK., Ku, HC., Lee, EJ., Tai, SH., Chen, FA., and Wu, TS. (2017). Anti-inflammatory Flavan-3-ol-dihydroretrochalcones from 
Daemonorops draco. J.Nat Prod, 80 (1):783-789.

Mairida, D., Muhadiono, M., \& Hilwan, I. (2016). Ethnobotanical Study of Rattans on Suku Anak Dalam Community in Bukit Duabelas Nasional Park. Biosaintifika: Journal of Biology \& Biology Education, $8 \quad(1), 64$. https://doi.org/10.15294/biosaintifika.v8i 1.5164

Mawardi, I., Nahar, \& Saifuddin. (2017). Ekstraksi Resin dari Buah Jernang (Dragon Blood) Metode UNDER Kritis Pelarut untuk Peningkatan Kualitas Mutu Resin Jernang Sesuai SNI 1671: 2010.Jurnal Teknologi Kimia Unimal 6:1 (Mei), 19.

Pasaribu, G., Waluyo, \& K, T. (2017). Aktivitas Antioksidan dan Antikoagulasi Resin Jernang (Antioksidant and Anticoagulation Activities of Dragons Blood). Jurnal Penelitian Hasil Hutan, 31 ( $\mathrm{D}$ e c e m b e r 2013 ). https://doi.org/10.20886/jphh.2013.31.4. 306-315

Perawati, S. (2017). Tradisional Plants Medicine of Suku Anak Dalam Jambi. Riset Informasi Kesehatan, 6(2), 510.

Ridhwan, M., Andalia, N., Armi., Yuhasriati. (2018). etnobotani jernang masyarakat pedalaman bireun. Biota, 11(2):158-168.

Risna, R. A. 2006 . Dragon's blood (Daemonorops draco BL.) tumbuhan obat yang menjanjikan dari Taman Nasional Bukit Tigapuluh. Warta Kebun Raya, Pusat Konservasi tumbuhan Kebun Raya Bogor - LIPI. Vol. 6.No. 1: 45 $-49$

Sulasmi, IS., Nisyawati., Purwanto, Y., Fatimah , S. (2012). Jernang rattan (Daemonorops draco) management by Anak Dalam Tribe in Jebak Village, Batanghari, Jambi Province. Biodiversitas, 13(3):151-160.

Syamsuardi, Mansyurdin, \& Witono, joko R. (2014). The Study of Genetic Diversity of Daemonorops draco (Palmae) using ISSR Markers. Biodiversitas, $\left.\begin{array}{lllllllllll} & 5 & ( & \mathrm{o} & \mathrm{k} & \mathrm{t} & \mathrm{o} & \mathrm{b} & \mathrm{e} & \mathrm{r}\end{array}\right)$, 109114.https://doi.org/10.13057/biodiv/d 150201

Waluyo, T. K. (2013). Perbandingan Sifat FisikoKimia 5 Jenis Jernang ( Comparative Study on Physico-chemical Properties of 5 Dragon s Blood Species ). 31(2), 141150.

Wang, YY., Dai, YW., Cao, J., Chen, YT., Zhao, CX., and Jiang, L. (2020). Eight new flavonoids from the fruits of Daemonorops draco. Fitoterapia, 143: 1-
7.

Yetti, Hardiyadi, B., \& Murni, P. (2013). Studi Etnobotani Jernang (Daemonorops spp). Pada Masyarakat Desa Lamban Sigatal dan Sepintun Kecamatan Pauh Kabupaten Sarolangun Jambi. Jurnal Biospecies, 6(Januari), 38-43.

Yi, T.; H.B. Chen.; Z.Z. Zhao.; Z.L. Yu and Z.H. Jiang. (2011). Comparison of the chemical profile and anti-platelet aggregation effects of two "Dragon's Blood" drugs used in traditional Chinese medicine. Journal of Ethnopharmacology 133 : 796-802. 